\title{
An Economic Evaluation of Freeze-Dried Kefir Starter Culture Production Using Whey
}

\author{
Y. Kourkoutas, V. Sipsas, G. Papavasiliou, and A. A. Koutinas ${ }^{1}$ \\ Food Biotechnology Group, Section of Analytical Environmental and Applied Chemistry, \\ Department of Chemistry, University of Patras, GR-26500 Patras, Greece
}

\begin{abstract}
An economic study is presented in which industrialscale production of freeze-dried kefir starter culture is discussed based on results on a laboratory scale. Industrial scale-up was based on a 3 -step process using 3 bioreactors of 100, 3,000, and 30,000 L for 300 $\mathrm{kg}$ of freeze-dried culture/d of plant capacity. The major cost component of the total investment was the freeze-drying machinery, which consisted of $57 \%$ of the total investment. Production cost was reduced from $€ 15.4 / \mathrm{kg}(\$ 18.5 / \mathrm{kg})$ to $€ 2.9 / \mathrm{kg}(\$ 3.5 / \mathrm{kg})$ when the production capacity was increased from 30 to $900 \mathrm{~kg} /$ d. An economic analysis revealed a 3.5-fold increase in production cost compared with the corresponding production cost of the wet product, with an added value of up to $€ 10.8 \times 10^{9}\left(\$ 13.0 \times 10^{9}\right)$ within the European Union.
\end{abstract}

Key words: kefir co-culture, freeze-dried starter culture, industrial scale-up, whey

\section{INTRODUCTION}

Nowadays, an upsurge of interest has been observed in providing suitable starter cultures for cheese production, because they give the final products consistent characteristics, which is an important feature for commerce. Many researchers have proposed a variety of cultures suitable as starters, including bifidobacteria (Boylston et al., 2004), Lactococcus (LitopoulouTzanetaki et al., 1993; Ryan et al., 1996; Kieronczyk et al., 2003; Michaelidou et al., 2003), Lactobacillus (Litopoulou-Tzanetaki et al., 1993; Kourkoutas et al., 2006a), Leuconostoc (Litopoulou-Tzanetaki et al., 1993), and Enterococcus (Litopoulou-Tzanetaki et al., 1993) species.

Kefir is a consortium of microbes that is mainly used in the production of the traditional low-alcoholic

Received August 27, 2006.

Accepted January 2, 2007.

${ }^{1}$ Corresponding author: A.A.Koutinas@upatras.gr
Russian drink kefir, in which milk constitutes the initial fermenting substrate. This mixed culture consists of various yeasts (Kluyveromyces, Candida, Saccharomyces, and Pichia); various lactic acid bacteria of the genus Lactobacillus, Lactococcus, and Leuconostoc; and acetic acid bacteria (Luis et al., 1993; Pintado et al., 1996; Garrote et al., 1997; Witthuhn et al., 2005). Yeasts and lactic acid bacteria coexist in a symbiotic relationship and are responsible for lacticalcoholic fermentation. Lactic acid bacteria that exist in the kefir grains have attracted considerable attention because of their ability to inhibit the development of spoilage and pathogenic microorganisms, either by the production of lactic acid or by the expression of antimicrobial agents (Rea and Cogan, 1994). In addition, the consumption of kefir has been related to a variety of health benefits (Cevikbas et al., 1994; Liu and Lin, 2000; Rodrigues et al., 2005). This mixed culture is able to utilize lactose; therefore, whey, which is rich in lactose, could be used as a raw material for kefir production (Koutinas et al., 2005).

Kefir yeast technology using whey as the raw material focuses on the production of new baker's yeast (Plessas et al., 2005), a simulated kefir drink (Athanasiadis et al., 2002; Kourkoutas et al., 2002; Paraskevopoulou et al., 2003a), single-cell protein for use as livestock feed or as a food additive (Paraskevopoulou et al., 2003b), and starter culture for cheese ripening (Kourkoutas et al., 2006b). The use of wet cultures is incompatible with commercial needs because of their physical status. Recently, we have studied freeze-dried kefir biomass production on a laboratory scale (G. Papavasiliou, Y. Kourkoutas, A. Rapti, V. Sipsas, M. Soupioni, and A. A. Koutinas, Food Biotechnology Group, Department of Chemistry, University of Patras, Greece, unpublished manuscript) as a technology that accommodates its use by the commercial sector. Hence, the present work represents an economic evaluation of freeze-dried kefir starter culture production for cheese ripening on an industrial scale based on previously reported results on a laboratory scale. 
Table 1. Optimal parameters for the production of kefir biomass using whey ${ }^{1}$

\begin{tabular}{lccrr}
\hline Parameter & $\begin{array}{c}\text { Fermentation } \\
\text { time, } \mathrm{h}\end{array}$ & $\begin{array}{c}\text { Biomass production, }{ }^{2} \\
\text { g of dry weight/L }\end{array}$ & $\begin{array}{c}\text { Lactic acid } \\
\text { concentration, g/L }\end{array}$ & $\begin{array}{c}\text { Daily biomass productivity, }{ }^{3} \\
\text { g of dry weight/L }\end{array}$ \\
\hline 0.5-mm pore of perforated tube & $38 \pm 2$ & $14.0 \pm 0.5$ & $6.0 \pm 0.4$ & $8.8 \pm 0.3$ \\
8.3-vvm ${ }^{4}$ airflow rate & $38 \pm 2$ & $14.0 \pm 0.5$ & $6.0 \pm 0.4$ & $8.8 \pm 0.3$ \\
$600 \mathrm{rpm}^{2}$ agitation & $17 \pm 1$ & $10.0 \pm 0.5$ & $6.2 \pm 0.2$ & $14.1 \pm 0.7$ \\
\hline
\end{tabular}

${ }^{1}$ G. Papavasiliou, Y. Kourkoutas, A. Rapti, V. Sipsas, M. Soupioni, and A. A. Koutinas, Food Biotechnology Group, Department of Chemistry, University of Patras, Greece, unpublished manuscript.

${ }^{2} \mathrm{~g}$ of dry weight/L of liquid volume of solution.

${ }^{3} \mathrm{~g}$ of dry weight/L of liquid volume of bioreactor.

${ }^{4} \mathrm{vvm}=$ ratio of air volume fed to the volume of ungassed broth in the fermenter per minute.

\section{MATERIALS and METHODS}

\section{Laboratory-Scale Experiments}

Kefir co-culture, isolated from the commercial "kefir" drink, was used in the present study. It was grown on a synthetic medium consisting of $4 \%$ lactose, $0.4 \%$ yeast extract, $0.1 \%\left(\mathrm{NH}_{4}\right)_{2} \mathrm{SO}_{4}, 0.1 \% \mathrm{KH}_{2} \mathrm{PO}_{4}$, and $0.5 \% \mathrm{MgSO}_{4} \cdot 7 \mathrm{H}_{2} \mathrm{O}$ at $30^{\circ} \mathrm{C}$. The synthetic medium was sterilized at $130^{\circ} \mathrm{C}$ for $15 \mathrm{~min}$ prior to use. Pressed wet cells $(\approx 0.5$ to $1.0 \mathrm{~g}$ dry weight) were prepared and used directly in aerobic fermentations of whey for further production of kefir co-culture, as described previously (G. Papavasiliou, Y. Kourkoutas, A. Rapti, V. Sipsas, M. Soupioni, and A. A. Koutinas, Food Biotechnology Group, Department of Chemistry, University of Patras, Greece, unpublished manuscript).

Whey was produced in the laboratory from commercial milk following a procedure similar to that of Fetatype cheese production. After heating the milk to $37^{\circ} \mathrm{C}$, commercial rennet $(0.01 \%)$ was added and the milk was left undisturbed for $2 \mathrm{~h}$ for curd formation. Subsequently, the curd was cut in squares (diameter $\approx 1 \mathrm{~cm}$ ), left undisturbed for $10 \mathrm{~min}$, and then clothfiltered at room temperature $\left(18\right.$ to $\left.22^{\circ} \mathrm{C}\right)$. It contained $\approx 5 \%$ lactose and $\approx 0.8 \%$ proteins.

Production of the freeze-dried kefir co-culture was carried out as described in a previous study (G. Papavasiliou, Y. Kourkoutas, A. Rapti, V. Sipsas, M. Soupioni, and A. A. Koutinas, Food Biotechnology Group, Department of Chemistry, University of Patras, Greece, unpublished manuscript). In brief, a kefir coculture produced by the aerobic fermentation of whey was resuspended in fermented whey (whey liquid after aerobic fermentation), which was used as a cryoprotective agent, and the mixture was then frozen to $-45^{\circ} \mathrm{C}$. The frozen samples were freeze-dried overnight at $5 \times 10^{2} \mathrm{~Pa}$ and at $-45^{\circ} \mathrm{C}$ in a freeze-drying system, Freezone 4.5 (Labconco, Kansas City, MO). Kefir cell viability after freeze-drying was $\approx 86 \%$ (G. Papavasiliou, Y. Kourkoutas, A. Rapti, V. Sipsas, M. Soupioni, and A. A. Koutinas, Food Biotechnology
Group, Department of Chemistry, University of Patras, Greece, unpublished manuscript). All laboratory experiments were carried out in triplicate, and the mean values are presented (standard deviation was approximately $\pm 5 \%$ ).

\section{Economic Analysis for Scale-Up of the Process}

Investment and production costs were estimated depending on plant capacity, based on optimal parameters for cell growth on a laboratory scale. Investment and production costs were based on the average commercial costs for machinery and consumables and on the average labor cost in the European Union. The added value created from the final product was estimated based on the market price of commercial dried baker's yeast.

\section{RESULTS and DISCUSSION}

\section{Optimization and Process Flow Sheet}

Table 1 summarizes the optimal values for biomass productivity and biomass concentration as affected by the airflow rate, pore size of the perforated tube, and air supply in the bioreactor (G. Papavasiliou, Y. Kourkoutas, A. Rapti, V. Sipsas, M. Soupioni, and A. A. Koutinas, Food Biotechnology Group, Department of Chemistry, University of Patras, Greece, unpublished manuscript). The results indicated that agitation significantly affected biomass productivity. The above experimental conditions were taken into consideration for the economic evaluation of scale-up. The proposed industrial flow sheet is presented in Figure 1. For the production of freeze-dried kefir biomass, it is necessary to produce wet kefir using a rotated vacuum filter to supply to the freeze-dryer. The biomass slurry is produced through 3 successively larger bioreactors, which carry out aerobic fermentation. Bioreactors of $100,3,000$, and $30,000 \mathrm{~L}$, connected to a heat exchanger to cool the fermenting medium, are supplied with sterilized air through a sterile filter. 


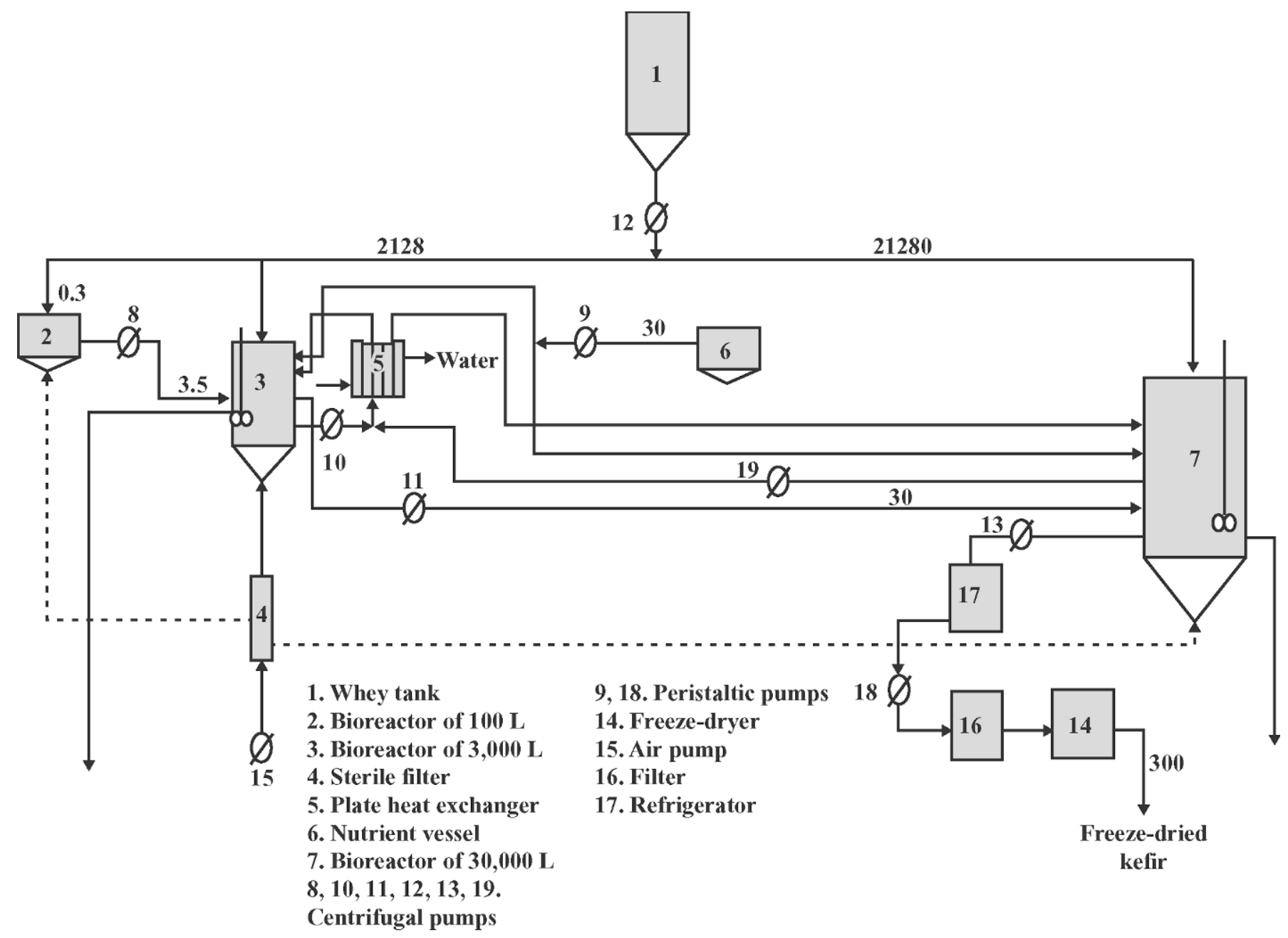

Figure 1. Process flow sheet with mass balance $(\mathrm{kg} / \mathrm{d})$ for a production capacity of $300 \mathrm{~kg}$ of dry weight/d.

Recently, scale-up of the aerobic fermentation of whey for single-cell protein production validated laboratory results, with acceptable fermentation efficiency parameters (Koutinas et al., 2005). The kefir biomass obtained from the pilot plant was of the same composition as the kefir biomass produced in the laboratoryscale bioreactor, because the anaerobic fermentation products using the kefir cultures described above were similar in terms of their chemical composition (unpublished data).

\section{Mass Balance and Investment}

All calculations were based on a production capacity of $300 \mathrm{~kg} / \mathrm{d}$ of freeze-dried kefir. An inoculum of 0.3 $\mathrm{kg}$ of wet kefir biomass is required to inoculate a 100$\mathrm{L}$ bioreactor and a $23,408-\mathrm{kg}$ amount of whey is supplied by a whey tank (Figure 1).
Based on the process flow sheet and mass balance, the investment was calculated according to the cost analysis presented in Table 2 . The results showed that

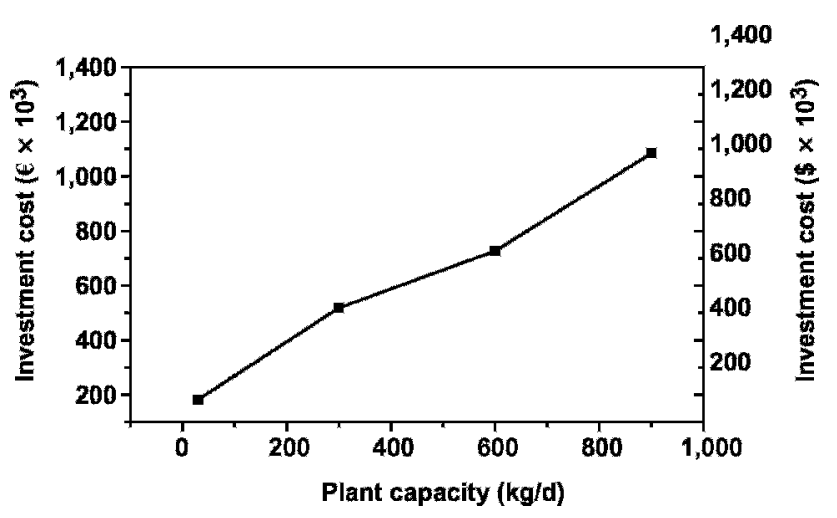

Figure 2. Dependence of investment cost on plant capacity.

Journal of Dairy Science Vol. 90 No. 5, 2007 
Table 2. Estimated investment cost of an industrial unit for $300 \mathrm{~kg} / \mathrm{d}$ of freeze-dried kefir starter culture production using whey

\begin{tabular}{lcc}
\hline Machinery & Quantity & Cost $(€ / \$)$ \\
\hline Centrifugal pump of $2 \mathrm{~m}^{3} / \mathrm{h}$ & 5 & $5,000 / 6,000$ \\
Centrifugal pump of $5 \mathrm{~m}^{3} / \mathrm{h}$ & 1 & $1,500 / 1,800$ \\
Peristaltic pump of $400 \mathrm{~L} / \mathrm{h}$ & 2 & $14,000 / 16,800$ \\
Pipes & - & $3,000 / 3,600$ \\
Plate heat exchanger & 1 & $10,000 / 12,000$ \\
Sterile filter & 1 & $3,000 / 3,600$ \\
Air pump & 1 & $1,500 / 1,800$ \\
Whey tank of 30,000 L & 1 & $5,000 / 6,000$ \\
Stainless-steel bioreactor of $100 \mathrm{~L}$ & 1 & $300 / 360$ \\
Stainless-steel bioreactor of 3,000 L & 1 & $5,000 / 6,000$ \\
Stainless-steel bioreactor of 30,000 L & 1 & $20,000 / 24,000$ \\
Refrigerator & 1 & $10,000 / 12,000$ \\
Vacuum filter & 2 & $30,000 / 36,000$ \\
Freeze-dryer of $350 \mathrm{~kg}$ ice-holding capacity & - & $300,000 / 360,000$ \\
Engineering & - & $50,000 / 60,000$ \\
Royalties & - & $60,000 / 72,000$ \\
Total investment cost & & $518,300 / 621,960$ \\
\hline
\end{tabular}

the major cost component of the total investment was due to the freeze-dryer machinery, which consisted of $57 \%$ of the total investment. It should also be stressed that the need for a centrifugal separator (which is expensive) was avoided because of the granular nature of the kefir biomass, which assists in the settling down of kefir grains (Koutinas et al., 2005).

The investment cost increased as the plant capacity increased, but the increase was not linear (Figure 2). Thus, the required investment per $100 \mathrm{~kg}$ of freezedried kefir biomass would be equal to $€ 173,100$ $(\$ 207,720)$ for a $300 \mathrm{~kg} / \mathrm{d}$ freeze-dried kefir plant capacity, whereas it would drop to $€ 120,500(\$ 144,600)$ for a $900 \mathrm{~kg} / \mathrm{d}$ kefir plant capacity. The investment cost could be further reduced upon installation of a production line using only one bioreactor system.

\section{Production Cost}

Production cost was mainly affected by productivity, and therefore by labor cost, steam consumption,

Table 3. Estimated cost for $300 \mathrm{~kg} / \mathrm{d}$ of freeze-dried kefir starter culture production using whey

\begin{tabular}{lcc}
\hline Parameter & Quantity & $\begin{array}{c}\text { Production } \\
\text { cost }(€ / \$)\end{array}$ \\
\hline Whey & $23,408 \mathrm{~L}$ & - \\
Labor cost & 20 workers & $800 / 960$ \\
Consumables & $30 \mathrm{~kg}$ of $\left(\mathrm{NH}_{4}\right) \mathrm{H}_{2} \mathrm{PO}_{4}$ & $30 / 36$ \\
Water requirements & $20 \mathrm{~m}^{3}$ & $60 / 72$ \\
Tap & $250 \mathrm{~m}^{3}$ & - \\
Cooling & Oil, $0.5 \mathrm{t}$ & - \\
Steam, 5 t & - & $150 / 300$ \\
Electricity & - & $170 / 204$ \\
Liquidation of debt & - & $1,460 / 1,752$ \\
Daily cost & - & \\
\hline
\end{tabular}

liquidation of debt, and electricity consumption. An analysis of the production cost is presented in Table 3. Raw material (whey) may have a negligible effect on the production cost, especially if the biomass production plant is located in the same area as a dairy industry. The cost would be further reduced if preexisting production lines were expanded rather than a new production plant established. The production cost would be reduced from $€ 15.4 / \mathrm{kg}$ ( $\$ 18.5 / \mathrm{kg}$ ) to $€ 2.9 / \mathrm{kg}$ $(\$ 3.5 / \mathrm{kg})$ if production capacity were increased from 30 to $900 \mathrm{~kg} / \mathrm{d}$ (Figure 3 ). This reduction was mainly attributable to the constant labor cost.

\section{Cost Comparison of Wet and Freeze-Dried Kefir}

The investment cost required for freeze-dried kefir was 4-fold higher than that of pressed wet kefir (Table 4), mainly because of the cost of the freeze-drying machinery. In addition, the production cost of freeze-

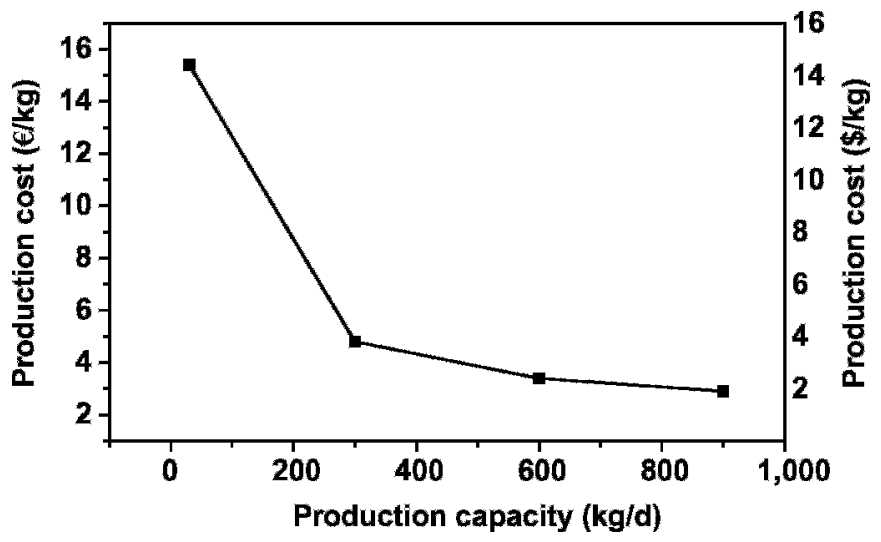

Figure 3. Dependence of production cost on production capacity. 
Table 4. Cost comparison of wet and freeze-dried kefir biomass ${ }^{1}$

\begin{tabular}{lccc}
\hline Type of kefir culture & $\begin{array}{c}\text { Investment } \\
\text { cost, } € / \$\end{array}$ & $\begin{array}{c}\text { Production cost, } \\
(€ / \mathrm{kg}) /(\$ / \mathrm{kg})\end{array}$ & $\begin{array}{c}\text { European Union } \\
\text { added value, } \\
€ \times 10^{9} / \$ \times 10^{9}\end{array}$ \\
\hline Wet kefir & $127,300 / 152,760$ & $1.4 / 1.7$ & - \\
Freeze-dried kefir & $518,300 / 621,960$ & $4.8 / 5.8$ & $10.8 / 13.0$ \\
\hline
\end{tabular}

${ }^{1}$ The results were calculated on the basis of $300 \mathrm{~kg}$ of dry weight of kefir biomass/d.

dried kefir was 3.5-fold higher than the corresponding production cost of the wet product because of the lower moisture content of the former.

\section{Technological Considerations}

Freeze-dried kefir biomass production has recently been studied extensively on a laboratory scale (G. Papavasiliou, Y. Kourkoutas, A. Rapti, V. Sipsas, M. Soupioni, and A. A. Koutinas, Food Biotechnology Group, Department of Chemistry, University of Patras, Greece, unpublished manuscript). The product has been used successfully as a starter culture in Fetatype cheese production, resulting in acceleration of cheese ripening, an improvement in quality characteristics, and increases in shelf life (Kourkoutas et al., 2006b).

According to the present study, the production cost of freeze-dried kefir culture was estimated at $€ 2.9 / \mathrm{kg}$ $(\$ 3.5 / \mathrm{kg})$. Taking into account that the market price of freeze-dried baker's yeast is about $€ 30 / \mathrm{kg}(\$ 36 / \mathrm{kg})$, a high added value was created, which was considered equal to $€ 10.8 \times 10^{9}\left(\$ 13.0 \times 10^{9}\right)$ for the European Union (Table 4). The costs presented would not be increased by more than $50 \%$ in Canada and the United States, taking into account mainly labor costs, because construction costs would not be extremely different compared with the European Union. The increase in daily expenses was counterbalanced by the high daily added value created. The difference between market value and production cost was further increased by considering that starter cultures are usually more expensive than baker's yeast. This low production cost would be feasible if the freeze-dried biomass production plant were installed in the same area as a dairy production unit to avoid whey transport. However, even if the production unit of a freeze-dried kefir biomass were located in an area some distance from a dairy production plant, transportation expenses would be counterbalanced by the high added value created, leading to a profitable investment.

\section{CONCLUSIONS}

As a final consideration, we concluded that freezedried kefir starter culture production on an industrial scale would offer the possibility for development of a marketable process. The variety of commercial products that could be developed in the framework of the above-mentioned technology would increase the potential for industrialization, because the business risk is reduced. Additional importance is acquired by the fact that production of the freeze-dried culture is based on whey, which would lead to increased loads of whey being used, thus minimizing the associated environmental problems.

\section{ACKNOWLEDGMENTS}

We thank the European Social Fund (ESF), Operational Program for Educational and Vocational Training II (EPEAEK II), and in particular, the Program PYTHAGORAS for funding this work.

\section{REFERENCES}

Athanasiadis, I., D. Boskou, M. Kanellaki, V. Kiosseoglou, and A. A. Koutinas. 2002. Whey liquid waste of the dairy industry as raw material for potable alcohol production by kefir granules. J. Agric. Food Chem. 50:7231-7234.

Boylston, T. D., C. G. Vinderola, H. B. Ghoddusi, and J. A. Reinheimer. 2004. Incorporation of bifidobacteria into cheeses: Challenges and rewards. Int. Dairy J. 14:375-387.

Cevikbas, A., E. Yemni, F. W. Ezzedenn, T. Yardimici, U. Cevikbas, and S. J. Stohs. 1994. Antitumoural, antibacterial and antifungal activities of kefir and kefir grain. Phytother. Res. 8:78-82.

Garrote, G. L., A. G. Abraham, and G. L. De Antoni. 1997. Preservation of kefir grains, a comparative study. Lebensm. Wiss. Technol. 30:77-84.

Kieronczyk, A., S. Skeie, T. Langsrud, and M. Yvon. 2003. Cooperation between Lactococcus lactis and nonstarter lactobacilli in the formation of cheese aroma from amino acids. Appl. Environ. Microbiol. 69:734-739.

Kourkoutas, Y., C. Psarianos, A. A. Koutinas, M. Kanellaki, I. M. Banat, and R. Marchant. 2002. Continuous whey fermentation using kefir yeast immobilized on delignified cellulosic material. J. Agric. Food Chem. 50:2543-2547.

Kourkoutas, Y., L. Bosnea, S. Taboukos, C. Baras, D. Lambrou, and M. Kanellaki. 2006a. Probiotic cheese production using Lactobacillus casei cells immobilized on fruit pieces. J. Dairy Sci. 89:1431-1451.

Kourkoutas, Y., P. Kandylis, P. Panas, J. S. G. Dooley, P. Nigam, and A. A. Koutinas. 2006b. Evaluation of freeze-dried kefir coculture as starter in Feta-type cheese production. Appl. Environ. Microbiol. 72:6124-6135.

Koutinas, A. A., I. Athanasiadis, A. Bekatorou, M. Iconomopoulou, and G. Blekas. 2005. Kefir yeast technology: Scale-up in SCP production using milk whey. Biotechnol. Bioeng. 89:788-796.

Litopoulou-Tzanetaki, E., N. Tzanetakis, and A. Vafopoulou-Mastrojiannaki. 1993. Effect of the type of lactic starter on microbiologi- 
cal, chemical and sensory characteristics of Feta cheese. Food Microbiol. 10:31-41.

Liu, J. R., and C. Lin. 2000. Production of kefir from soymilk with or without added glucose, lactose or sucrose. J. Food Sci. 65:716-719.

Luis, A., E. Lopez, and C. Lema. 1993. Microflora present in kefir grains of the Galician region. J. Dairy Res. 60:263-267.

Michaelidou, A., M. C. Katsiari, E. Kondyli, L. P. Voutsinas, and E. Alichanidis. 2003. Effect of a commercial adjunct culture on proteolysis in low-fat Feta-type cheese. Int. Dairy J. 13:179-189.

Paraskevopoulou, A., I. Athanasiadis, G. Blekas, A. A. Koutinas, M. Kanellaki, and V. Kiosseoglou. 2003a. Influence of polysaccharide addition on stability of a cheese whey kefir-milk mixture. Food Hydrocol. 17:615-620.

Paraskevopoulou, A., I. Athanasiadis, M. Kanellaki, A. Bekatorou, G. Blekas, and V. Kiosseoglou. 2003b. Functional properties of single cell protein produced by kefir microflora. Food Res. Int. $36: 431-438$
Pintado, M. E., J. A. Lopes Da Silva, P. B. Fernades, F. X. Malcata, and T. A. Hogg. 1996. Microbiological and rheological studies on Portuguese kefir grains. Int. J. Food Sci. Technol. 31:15-26.

Plessas, S., L. Pherson, A. Bekatorou, P. Nigam, and A. A. Koutinas. 2005. Bread making using kefir grains as baker's yeast. Food Chem. 93:585-589.

Rea, M. C., and T. M. Cogan. 1994. Buttermilk plants: The Irish version of kefir. Ir. Scientist 2:7.

Rodrigues, K. L., L. R. Gaudino Caputo, J. C. Tavares Carvalho, J. Evangelista, and J. M. Schneedorf. 2005. Antimicrobial and healing activity of kefir and kefiran extract. Int. J. Antimicrob. Agents 25:404-408.

Ryan, M. P., M. C. Rea, C. Hill, and R. P. Ross. 1996. An application in Cheddar cheese manufacture for a strain of Lactococcus lactis producing a novel broad-spectrum bacteriocin, lacticin 3147. Appl. Environ. Microbiol. 62:612-619.

Witthuhn, R. C., T. Schoeman, and T. J. Britz. 2005. Characterisation of the microbial population at different stages of kefir production and kefir grain mass cultivation. Int. Dairy J. 15:383-389. 